\title{
Immune Components of Liver Damage Associated with Connective Tissue Diseases
}

\author{
Aziz A. Chentoufi ${ }^{1,2}$, Youri A. Serov ${ }^{3}$, Mansour Alazmi ${ }^{1}$ and Kamaldeen Baba ${ }^{4}$ \\ ${ }^{1}$ Department of Immunology, Pathology and Clinical Laboratory Medicine, King Fahad Medical City, Riyadh, Saudi Arabia; \\ ${ }^{2}$ Faculty of Medicine, King Saud Ben AbdulAziz University-Health Sciences, King Fahad Medical City, Riyadh; ${ }^{3}$ Laboratory of \\ Clinical Genetic, Research Institute of Gerontology, Ministry of Health, Leonova 16, Moscow, Russia; ${ }^{4}$ Department of \\ Microbiology, Pathology and Clinical Laboratory Medicine, King Fahad Medical City, Riyadh, Saudi Arabia
}

\begin{abstract}
Autoimmune connective tissue diseases are associated with liver abnormalities and often have overlapping pathological and clinical manifestations. As a result, they can present great clinical challenges and evoke questions about diagnostic criteria for liver diseases. Moreover, discriminating between liver involvement as a manifestation of connective tissue disease and primary liver disease can be challenging since they share a similar immunological mechanism. Most patients with connective tissue diseases exhibit liver test abnormalities that likely result from coexisting, primary liver diseases, such as fatty liver disease, viral hepatitis, primary biliary cirrhosis, autoimmune hepatitis, and drug-related liver toxicity. Liver damage can be progressive, leading to cirrhosis, complications of portal hypertension, and liver-related death, and, therefore, must be accurately identified. In this review, we highlight the challenges facing the diagnosis of liver damage associated with connective tissue disease and identify immune mechanisms involved in liver damage associated with connective tissue diseases.

(C) 2014 The Second Affiliated Hospital of Chongqing Medical University. Published by XIA \& HE Publishing Ltd. All rights reserved.
\end{abstract}

\section{Introduction}

The liver is the largest lymphoid organ of the body and is known to be involved in the immune response against pathogens and the maintenance of tolerance to

Keywords: Systemic lupus erythematosus; Antiphospholipid syndrome; Autoimmune hepatitis; Rheumatoidarthritis; Sjögren's syndrome; Scleroderma; Abnormal liver tests.

Abbreviations: AIH, autoimmune hepatitis; ANA, antinuclear antibody; ALP, alkaline phosphatase; ALT, alanine transaminase; aPS, antiphospholipid syndrome; AST, aspartate transaminase; CTD, connective tissue disease; ELISA, enzyme linked immunoassay; GGT, gamma glutamyltransferase; IIF, indirect immunofluorescence; $\mathrm{NRH}$, nodular regenerative hyperplasia; $\mathrm{PBC}$, primary biliary cirrhosis; PSC, primary sclerosing cholangitis; RA, rheumatoid arthritis; SS, Sjögren's syndrome; SLE, systemic lupus erythematosus; SSc, systemic sclerosis.

Received: 21 December 2013; Revised: 2 February 2014; Accepted: 4 February 2014

DOI of original article: 10.14218/JCTH.2014.00001.

Correspondence to: Aziz A. Chentoufi, Department of Immunology, Pathology and Clinical Laboratory Medicine, King Fahad Medical City, Riyadh 11525, Saud Arabia. Tel: +966-1288-9999 x14736, Fax: +966-1288-9999 X12675, E-mail: aachentoufi@kfmc.med.sa self-molecules. ${ }^{1,2}$ In autoimmune diseases, such as systemic lupus erythematosus (SLE), rheumatoid arthritis (RA), primary Sjögren's syndrome (SS), myositis, antiphospholipid syndrome (aPS), Behcet's syndrome, scleroderma and vasculitis, primary biliary cirrhosis (PBC), and primary sclerosing cholangitis (PSC), liver damage can occur from an autoimmune reaction. It may produce a biochemical picture of cholestatic damage (with elevated alkaline phosphatase (ALP) and gamma glutamyltransferase (GGT)) or hepatocellular (with elevated alanine transaminase (ALT) and aspartate transaminase (AST)). Advanced disease with liver failure and cirrhosis is extremely rare in patients with connective tissue disease. Many descriptive case studies of patients with SLE, SS and systemic sclerosis (SSc), serologic liver test alterations, and histological lesions have been found (Table 1). In the majority of cases, liver histology demonstrated only minor changes, and the coexisting primary liver disease was often overlooked. The mechanism of elevated portal vein pressure and the pathological changes causing portal hypertension vary with each disease. Portal hypertension is commonly classified according to the location of obstructive changes along the vascular system: prehepatic, intrahepatic, and post-hepatic with intrahepatic portal hypertension further subdivided into pre-sinusoidal and post-sinusoidal. A typical example of prehepatic portal hypertension is extrahepatic portal vein thrombosis, while a purely post-hepatic portal hypertension example is the Budd-Chiari syndrome (BCS) commonly due to membranous obstruction of the inferior vena cava. ${ }^{3-5}$ Nevertheless, the main cause of biochemical liver abnormalities in patients with connective tissue diseases (CTD) is treatment with potentially hepatotoxic drugs or coexisting viral hepatitis. ${ }^{1}$ Fibrotic autoimmune diseases are characterized pathogenetically by an inflammatory process that induces and sustains robust fibrosis. This is due to the production of an array of biological factors activating fibroblast proliferation and collagen secretion. While advanced liver disease such as cirrhosis and liver failure are rare in patients with CTD, abnormal liver function tests are quite common, ${ }^{6}$ and liver histology may reveal a variety of subclinical liver diseases. In particular, unusual liver lesions, such as nodular regenerative hyperplasia (NRH), have been reported with increasing frequency in patients with $\mathrm{CTDs}^{7,8}$ (Table 2). On the other hand, acute or progressing liver involvement is generally related to viral hepatitis reactivation or to a concomitant autoimmune liver disease. $^{1}$ 
Table 1. Diagnostic feature of autoimmune liver diseases

\begin{tabular}{|c|c|c|}
\hline Disease & Markers & Histology \\
\hline \multirow[t]{4}{*}{ Anti-phospholipid syndrome } & $\mathrm{aPL}, \mathrm{aCL}$ & Nodular regenerative hyperplasia \\
\hline & Budd-Chiari syndrome & \\
\hline & Hepatosplenomegaly & \\
\hline & Jaundice & \\
\hline \multirow[t]{4}{*}{ Felty's syndrome } & Raised ALT & Kupffer cell hyperplasia \\
\hline & Hepatomegaly & Steatosis \\
\hline & Portal hypertension & Mild portal tract fibrosis \\
\hline & Raised ALP & Nodular regenerative hyperplasia \\
\hline \multirow[t]{2}{*}{ Myositis } & Jaundice & Chronic active hepatitis (rare) \\
\hline & Raised ALP & Primary biliary cirrhosis \\
\hline \multirow[t]{2}{*}{ Rheumatoid arthritis } & Raised ALP & Kupffer cell hyperplasia \\
\hline & Raised $\gamma$-glutamyltransferase & Steatosis \\
\hline \multirow[t]{3}{*}{ Scleroderma } & Hepatomegaly & Cirrhosis \\
\hline & Prothrombin time & Primary biliary cirrhosis \\
\hline & Jaundice Raised liver enzymes & Nodular regenerative hyperplasia \\
\hline \multirow[t]{3}{*}{ Sjögren's syndrome } & Raised liver enzymes & Primary biliary cirrhosis \\
\hline & Jaundice & Chronic active hepatitis \\
\hline & AMA, anti-Ro/La & Cryptogenic cirrhosis \\
\hline \multirow[t]{4}{*}{ Systemic lupus erythematosus } & Anti- DS DNA & Steatosis \\
\hline & Hepatomegaly & Chronic active hepatitis \\
\hline & Jaundice & \\
\hline & Raised ALT & \\
\hline
\end{tabular}

Table 2. Liver Pathologies in patients with autoimmune diseases

\begin{tabular}{|c|c|}
\hline Pathology & Description \\
\hline $\begin{array}{l}\text { Chronic active hepatitis } \\
(\mathrm{CAH})\end{array}$ & $\begin{array}{l}\text { Piecemeal necrosis defined as the destruction of liver cells at the interface between parenchyma } \\
\text { and connective tissue with a predominantly mononuclear inflammatory infiltrate. Aggregation of } \\
\text { lymphocytes and macrophages surrounds the hepatocytes with a spreading wave of necrosis. As } \\
\text { the liver parenchyma is destroyed, sheets of connective tissue are laid down, which initially contain } \\
\text { an inflammatory infiltrate resulting in a "maple leaf" configuration to the portal tract. }\end{array}$ \\
\hline $\begin{array}{l}\text { Chronic persistent } \\
\text { hepatitis }(\mathrm{CPH})\end{array}$ & $\begin{array}{l}\mathrm{CPH} \text { is characterized by chronic inflammatory infiltration of portal tracts with preserved lobular } \\
\text { architecture and little or no portal fibrosis with expanded tracts. There is no significant piecemeal } \\
\text { necrosis. } \mathrm{CPH} \text { disease is mostly stationary and in many instances resolves spontaneously, far more } \\
\text { frequently than CAH. }\end{array}$ \\
\hline Hepatomegaly & $\begin{array}{l}\text { Defined clinically as a palpable liver and usually, but not always, confirmed by ultrasound or CT } \\
\text { scanning or at post mortem. }\end{array}$ \\
\hline Lipoid hepatitis & $\begin{array}{l}\text { A combination of CAH with LE cell phenomena. May be distinguished from SLE by the absence of } \\
\text { antibodies to double stranded DNA. }\end{array}$ \\
\hline $\begin{array}{l}\text { Nodular regenerative } \\
\text { hyperplasia of the liver }\end{array}$ & $\begin{array}{l}\text { Characterized by diffuse nodularity of the liver with little or no fibrosis and has been found in } \\
\text { association with autoimmune disease, drug treatment, and a variety of hematological disorders. }\end{array}$ \\
\hline \multirow[t]{5}{*}{ Primary biliary cirrhosis } & $\begin{array}{l}\text { PBC is an autoimmune inflammatory disorder associated with a high serum titer of anti- } \\
\text { mitochondrial antibodies. Histological appearance is divided into four stages: }\end{array}$ \\
\hline & (I) florid bile-duct lesions with lymphoid aggregates \\
\hline & (II) ductular proliferation \\
\hline & (III) scarring (septal fibrosis and bridging) \\
\hline & (IV) cirrhosis \\
\hline $\begin{array}{l}\text { Primary sclerosing } \\
\text { cholangitis }\end{array}$ & $\begin{array}{l}\text { A chronic inflammatory disorder with fibrosis and obliteration of the bile ducts. It is strongly } \\
\text { associated with inflammatory bowel. }\end{array}$ \\
\hline
\end{tabular}




\section{Systemic lupus erythematosus}

SLE is a chronic autoimmune disease that affects multiple organs and presents with diverse clinical and serological manifestations. It affects principally women during the child bearing years. Although it is very unusual to find significant hepatic dysfunction in SLE patients, unusual liver complications have been linked to the treatment with potentially hepatotoxic drugs or viral hepatitis. Careful exclusion of such causative factors raises challenges regarding differential diagnosis between liver disease associated with SLE and primary liver disease having clinical and diagnostic features resembling SLE. ${ }^{9}$ The differential diagnosis between autoimmune hepatitis and SLE-associated hepatitis remains a clinical challenge and better diagnostic criteria for both diseases need to be established. A current definition of (lupoid) autoimmune hepatitis includes histological evidence of chronic active hepatitis, positive antinuclear antibodies or LE cells, and exclusion of any other causes, including possible viral causes. It can usually be distinguished from SLE by the absence of antibodies to double-stranded DNA.

The reported frequency of hepatic involvement in SLE is 8$23 \% .{ }^{10-12}$ It consists of several pathophysiological features, and clinical signs, including hepatomegaly (39\%), splenomegaly $(6 \%)$, jaundice $(24 \%)$, and elevations of liver enzymes or abnormal liver histology $(21 \%) .{ }^{13}$ According to a retrospective study conducted by Gibson and Myers, abnormal values were present in $55 \%$ of 81 patients diagnosed with SLE, and $29 \%$ of those had no cause for the documented changes other than SLE. In a study by Miller et al., liver enzyme levels were elevated in $23 \%$ of 260 patients with SLE. ${ }^{14,15}$ The reported incidence of hepatomegaly in SLE varied from $12-55 \%$ depending on the series. Cholestatic hepatitis emerging as conjugated hyperbilirubinemia can develop in a background of neonatal lupus erythematosus, an uncommon passive autoimmune disease caused by transplacental passage of anti-Ro/SSA and/or anti-La/SSB and antiU1RNP maternal autoantibodies. In this condition, idiopathic portal hypertension can be accompanied by splenomegaly, cytopenia, and esophageal varices. ${ }^{16}$

In a histologic review of 73 patients with SLE, Matsumoto et al. identified a number of coexisting primary liver disorders: fatty liver (73\%), nodular regenerative hyperplasia $(\mathrm{NRH})(7 \%)$, viral hepatitis $(4 \%)$, PBC $(3 \%)$, and autoimmune hepatitis (3\%). ${ }^{17}$ Case reports have been published describing additional liver diseases in patients with SLE; including primary sclerosing cholangitis, ${ }^{18}$ autoimmune cholangiopathy, granulomatous hepatitis, ${ }^{19}$ and idiopathic portal hypertension. ${ }^{20}$ Vascular disorders of the liver secondary to antiphospholipid syndrome associated with SLE include $\mathrm{BCS}$, hepatic infarction, and hepatic rupture. ${ }^{21,22}$

Autoimmune hepatitis ( $\mathrm{AIH}$ ) and lupus-associated hepatitis can be difficult to differentiate given their common clinical and serologic manifestations. Histologic findings may be helpful as AIH characteristically shows periportal inflammation and piecemeal necrosis with dense lymphoid infiltrates, whereas lupus-associated hepatitis shows predominantly mild lobular inflammation without piecemeal necrosis on histology. ${ }^{23-26}$ Anti-ribosomal $P$ antibodies, which are not found in patients with $\mathrm{AIH}$, are present in a significant proportion $(69 \%)$ of patients with lupus-associated hepatitis and may aid in differentiating the two entities. ${ }^{16}$ Clarifying the diagnosis has important prognostic and therapeutic implications, as lupus-associated hepatitis has a more benign course and does not require corticosteroid therapy. 27,28

The liver is generally not a major target organ for damage in SLE, and, as such, abnormalities of liver function are not included in classification and diagnostic criteria for SLE. Abnormal liver function tests are common in SLE, being found in up to $50 \%$ of patients at some point of the disease course, ${ }^{13,14}$ and the main causes are disease activity, drug toxicity, and rarely an overlapping primitive autoimmune liver disease. In $23 \%$ of patients with SLE and liver test abnormalities, no cause for liver test abnormality was identified. Elevated liver tests were shown to correlate with disease activity $^{15}$ and to improve with steroid treatment. ${ }^{13}$

\section{Antiphospholipid syndrome}

APS is characterized by a wide variety of hemocytopenic and vaso-occlusive manifestations, including acquired thrombosis, recurrent fetal losses, and thrombocytopenia associated with autoantibodies directed against phospholipids (antiphospholipid antibodies or aPLs), mainly cardiolipin antibodies (anticardiolipin antibodies $(\mathrm{aCL}))^{29-31}$ Recently, $\beta 2$-glycoprotein-I (b2GPI) was described as one of the major target antigens for aPLs. ${ }^{32,33}$ The aPLs have been found in many conditions, such as infection, malignancy, and drugs use. Also, they were found in $5 \%$ of healthy people without risk for thrombosis. Therefore, aPLs may be primary when there is no other condition and secondary when there are other conditions, such as SLE, RA, or SSc. ${ }^{34}$

APS has been described rarely in patients with autoimmune hepatitis. ${ }^{16,35-37}$ APLs are found in many liver diseases, such as chronic hepatitis C (HCV), where they can cause thrombosis and thrombocytopenia. Infection with HCV is present in $7 \%$ of patients with thrombotic disorders and anticardiolipin antibodies, and they can also cause BCS. Patients with autoimmune hepatitis and a history of thrombosis or fetal loss must undergo testing for aPS. ${ }^{38-41}$

APS-related liver manifestations are mainly of vascular origin, including thrombosis of major arterial or venous vessels based on microthrombosis. However, non-thrombotic liver injury has also been reported. Moreover, aPLs were shown to be involved in small artery intrahepatic damage and in the pathogenesis of NRH, while cases of BCS were reported in association with APS in $5 \%$ of the cases. ${ }^{42,43}$ The association of aPL positivity with BCS was described for the first time in a report in 1984, and since then, a few more cases have been described in literature. BCS is a clinical and pathological entity characterized by structural and functional abnormalities of the liver resulting from obstruction of the outflow of hepatic venous blood. The role of $\mathrm{APL}$ in BCS is unclear, and it has been suggested that the aPL production is just secondary to the liver damage. However, in other reports, aPLs were detected before the onset of the syndrome. The findings strongly suggest that $\mathrm{APL}$ may be the cause of the syndrome. BCS might be considered as the first clinical manifestation of aPS.

\section{Rheumatoid arthritis}

RA is a systemic autoimmune disease characterized by joint involvement and a number of extra-articular manifestations. RA, Still's disease, and Felty's syndrome are rheumatoid syndromes sharing a common immunological profile. ${ }^{44,45}$ Liver involvement has been documented in up to $6 \%$ of 
patients with RA, presenting in most cases as mild elevations in ALP and serum GGT levels. ${ }^{46,47}$ Clinical manifestations rarely include spontaneous hepatic rupture in patients complicated by extra-articular features and high titers of rheumatoid factor or mild sero-negative inflammatory arthritis. It can be attributed to necrotizing hepatic arteritis with infarction and spontaneous liver rupture. ${ }^{48,49}$ PBC may also develop. ${ }^{50,51}$

In a recently published survey, nonspecific changes, such as inflammatory cell infiltration of the portal tracts, small scattered foci of liver cell necrosis, increased centrilobular lipofuscin deposits, and occasional fat containing hepatocytes, were reported in $74 \%$ of 31 RA patients. ${ }^{52}$ However, a review of liver biopsy findings in patients with RA did not identify a consistent structural abnormality. Most biopsy reports suggested only minor nonspecific changes. In 117 patients with RA without extra-articular complications, 35\% of liver biopsy specimens were normal, $43 \%$ showed nonspecific hepatitis, and $22 \%$ were associated with fatty change. ${ }^{53}$ In another group of 31 patients with more severe RA and biochemical evidence of liver dysfunction, 23 (74\%) liver biopsy specimens had nonspecific reactive changes, 4 $(13 \%)$ suggested chronic liver disease, and only four were normal. Of the 13 patients with chronic liver disease, one of each of the following diagnoses were made: PBC, chronic active hepatitis, alcoholic cirrhosis, and amyloidosis. Because primary liver disease was found in $30 \%$ of cases, the changes attributed to RA may have been overestimated. Although liver biopsies are not done routinely in the management of RA, the results of most liver biopsies are consistent with chronic inflammation. ${ }^{54}$ These findings suggest that, except for mild elevation in levels of serum aminotransferases, liver abnormalities are not common in RA.

Patients with unexplained liver abnormalities require further testing to exclude autoimmune hepatitis, alcoholic cirrhosis, amyloidosis, and PBC. Histologic findings in patients with RA are variable. In a retrospective review study of RA patients autopsies, Ruderman et al. found that the majority of samples had hepatic congestion, steatosis, and portal tract inflammation, whereas only 15 cases had normal liver parenchyma. ${ }^{55}$ However, Rau and colleagues have shown only mild and generally nonspecific changes in liver biopsies from patients with RA. ${ }^{56}$

In RA patients, wide ranges of primary liver disorders have been reported, including $\mathrm{PBC}$, autoimmune hepatitis, and autoimmune cholangiopathy. Other rare conditions, including $\mathrm{NRH}$, idiopathic portal hypertension, and spontaneous hepatic rupture secondary to vasculitis, have also been reported. ${ }^{49,57-60,61}$ RA is generally defined as the combined presence of arthropathy and the rheumatoid factor (RF). However, similarity in extrahepatic manifestations of primary liver disorders might be confusing. Autoantibodies, such as anti-cyclic citrullinated peptide (anti-CCP), have been shown to be reliable markers for RA compared with arthropathy associated with chronic $\mathrm{HCV}$, AIH, or PBC. ${ }^{62}$

\section{Sjögren's syndrome}

SS is an autoimmune disease that typically presents with dryness of eyes (keratoconjuctivitis sicca) and mouth (xerostomia). Other organs such as liver, spleen, lung, and kidney may be involved. Abnormal liver tests with increased AST and ALT have been reported with and without RA. In primary SS, studies have shown the presence of anti-mitochondrial antibodies (AMA). ${ }^{47}$ Half of patients with both SS and rheumatoid arthritis and $10 \%$ of those with primary SS have positive AMA similar to $\mathrm{PBC}$ with evidence of hepatic disease. ${ }^{63-65}$

Specific liver disease was detected in $50 \%$ of SS patients with liver test abnormalities. In the remaining $50 \%$ of patients, there was no explanation for the liver test abnormality, ${ }^{66}$ which is similar to other studies. ${ }^{66,67}$ In general, AMA detection was usually accompanied by histopathologic abnormalities consistent with PBC. In a series of 300 patients with SS, serum liver enzyme elevations and AMA screening found that $7 \%$ of patients with SS had either subclinical ( $2 \%)$ or asymptomatic (5\%) liver disease as manifested by elevated liver enzyme levels and positive AMA test results. ${ }^{65,68}$ In this large study, chronic active hepatitis or cirrhosis was rarely observed. It was concluded that liver involvement in primary SS is rare and subclinical, but can present with histopathologic features of PBC. AMA is the most sensitive indicator of underlying liver pathology in primary SS patients. ${ }^{69,70}$ Long-term follow-up of these patients might be required to determine the risk of progression and treatment follow-up.

Some studies regarding hepatic involvement in SS have attempted to evaluate a causal role for HCV in the pathogenesis of SS. One study found a $13 \%$ prevalence of chronic HCV in these patients, with histopathologic evidence of chronic active hepatitis in those who underwent biopsy. ${ }^{67}$ It was suggested that the coexistence of HCV and SS explains the higher incidence of cirrhosis and chronic active hepatitis in these patients. Alternatively, the prevalence of HCV in the patients studied may have contributed to the pathogenesis of SS in certain cases. Several studies have shown that the prevalence of chronic HCV infection among patients with SS was higher than the general population, ranging from $12 \%$ to $19 \% .^{71,72}$ The presence of sicca symptoms (dryness of the eyes and mouth), lymphocytic infiltration of salivary glands, and serum autoantibodies in patients with HCV infection suggested that HCV may even be the cause of SS in some cases. Other investigators, however, pointed out subtle differences in the clinical, immunologic, and histologic characteristics of patients between HCV-related SS and primary SS patients without HCV infection (e.g., a lower prevalence of sicca symptoms, a lower frequency of anti-Ro/ SS-A and anti-La/SS-B antibodies, and a higher prevalence of cryoglobulinemia and hypocomplementemia). The pathogenic role of $\mathrm{HCV}$ in SS remains unclear, although $\mathrm{HCV}$ infection may be involved in the pathogenesis of SS in subgroups of patients. Conversely, HCV infection may produce extrahepatic manifestations that may mimic SS. ${ }^{71-75}$ In clinical practice, it is reasonable to recommend that abnormal liver parameters in patients with SS should prompt testing for $\mathrm{HCV}$ infection.

The pathogenic process underlying hepatic (mainly in the case of PBC) and salivary gland damage and destruction could be similar because both epithelial populations inappropriately express class II HLA molecules and CD4 (+) T cells predominate. In each case, the autoimmunity profile is easily distinguishable due to the wide range of differentiating antibodies (in primary SS, anti-Ro and anti-La antibodies predominate, while in $\mathrm{PBC}$, the predominant specific autoantibodies are anti-mitochondrial antibodies-AMA). Autoantibodies as serological markers are clinically valuable in the prediction of autoimmune liver diseases in SS. In patients with AMA who develop PBC, the titer of smooth 
muscle antibodies (SMA) is higher. Antinuclear antibodies are the most specific markers for autoimmune hepatitis. ${ }^{68}$ AMA was suggested to be the most sensitive marker for the detection of underlying PBC in patients with primary SS. ${ }^{69}$ In several series, the prevalence of PBC was reported to be approximately $6 \%$. Histological evidence of focal sialadenitis was detected in $95 \%$ of patients with PBC, and anti-La antibodies were detected in sera from $38 \%$ of patients with PBC. ${ }^{70}$ An overlap between CREST, SS, thyroid hyperplasia, and chronic hepatitis has been reported. ${ }^{76}$

\section{Systemic sclerosis}

Systemic sclerosis (scleroderma SSc) is a multiple organ disease with inflammation and fibrosis that regularly involves the skin and the blood vessels; other organs such as lungs, heart, gastrointestinal tract, kidneys, and musculoskeletal system are frequently affected. ${ }^{77}$ Scleroderma is classified into two major subsets, which are distinguished by the extent of skin thickening: limited and diffuse cutaneous scleroderma. ${ }^{78}$

Primary biliary cirrhosis is the most commonly reported liver disorder in patients with SSc. Scleroderma occurrence in patients with primary biliary cirrhosis is between $7 \%$ and $12 \% .{ }^{79,80}$ Only a minority of patients with primary biliary cirrhosis-associated SSc show the diffuse type of SSc, rather than the limited cutaneous type, and they generally have a positive AMA. Also, they commonly have anticentromere Ab, an antibody frequently found in patients with limited cutaneous SSc. ${ }^{79-81}$ Therefore, testing for anticentromere $A b$ may be helpful in the evaluation of SSc in patients with known primary biliary cirrhosis. Although the liver disease in patients with primary biliary cirrhosis-associated SSc may progress to cirrhosis and result in liver-related morbidity, mortality is more commonly due to other systemic complications of SScand not the liver disease. ${ }^{79}$

Fibrotic autoimmune diseases are characterized by an inflammatory process, which induces and sustains robust fibrosis. This is due to the expression of large number of biological factors which activates fibroblast proliferation and collagen secretion. Among the various fibrogenic factors in autoimmune diseases, interleukin-1 (IL-1), IL- 6 , and TGF- $\beta$ have a relevant role. ${ }^{82,83}$ Interestingly, these three cytokines are also involved in generation/differentiation and activity of a particular $T$ cell subpopulation, the Th17 cells. Th17 lymphocytes constitute a T cell subtype characterized by the capacity to produce and secrete IL17. This T helper cell subset is independent of typical Th1 and Th2 subpopulations, which secrete either IFN- $\gamma$ or IL-4/IL-5/IL-13, respectively. ${ }^{84}$ Recent studies clarified the requirements for Th17 lymphocyte differentiation from circulating naïve or memory CD4+ T cells. When naïve T cells are the starting population for Th17 cell generation, a cytokine milieu of pro-inflammatory factors (such as IL-1 $\beta$, IL-6, IL-23, IL-21) and low TGF- $\beta$ levels is required to induce the Th17 profile. When CD4+ memory $T$ cells are the Th17 precursors, IL-21 and IL-23 are required to expand and stabilize the commitment of Th17 lymphocytes. In this instance, Th17 cells release an array of effector cytokines including, IL-17A, IL-17F, IL-22, and IL-26. At the molecular level, IL-6, IL-21, and IL-23 together with low TGF $\beta$ concentration induce expression of STAT3 and ROR $\gamma$ t transcription factors that are involved in Th17 differentiation. ${ }^{85-89}$

Importantly, abnormal activation/expansion of Th17 cells linked to the activity of inflammatory cytokines such as IL-6 and IL-23 has been shown to correlate with autoimmune diseases such as multiple sclerosis (MS), RA, inflammatory bowel disease, and psoriasis. ${ }^{90-98}$ Recently, analysis of liver infiltrating cells suggested that immune responses skewed toward Th17 cell generation could be involved in the pathogenesis of PBC in humans. In fact, the immunohistochemical analysis of liver specimens from control and PBC subjects demonstrated a significantly higher concentration of IL17-positive cells in patients compared to controls. ${ }^{99}$ Th17 cell expansion was a common feature associated with a relative contraction of Th1 responses.

Concerning the regulatory $\mathrm{T}$ cell compartment, quantitative and qualitative alterations were observed in both diseases. However, while PBC patients showed defects only in the CD8+ Treg subset, SSc patients showed abnormalities in both CD4+, and CD8+ Treg subpopulations. The CD8+ Treg subset seemed to be the most active in the pathogenic cascade leading to fibrotic disease onset and maintenance. ${ }^{100}$ Dendritic cells also play a major role in inflammatory process associated with liver fibrosis. ${ }^{101}$

A study by Connolly and colleagues ${ }^{102}$ found a potential role for dendritic cells in mediating the proinflammatory environment in a model of liver fibrosis induced by six weeks of three-times-weekly injections of thioacetamide and leptin. CD11c+ cells accumulated in the fibrosed livers and were a mixed population. However, many expressed MHCII and CD40. The isolated CD11c+ cells stimulated natural killer cells and T cells in vivo and in vitro, suggesting that these CD11c+ cells were comprised of, at least in part, true dendritic cells. Depletion of $\mathrm{CD} 11 \mathrm{c}+$ cells resulted in remarkable reductions in the levels of TNF- $\alpha$, IL- 6 , and other inflammatory cytokines in the cultures of nonparenchymal cells, indicating a role for CD11c+ cells in initiating or sustaining a proinflammatory environment in the fibrosed liver. ${ }^{102}$ Also, CD11c+ cells cultured with hepatic stellate cells can adopt a proinflammatory phenotype or differentiate into myofibroblasts during activation, ${ }^{103}$ resulting in increased expression of proinflammatory mediators and increased proliferation of hepatic stellate cells.

This supports the notion that dendritic cells can directly modulate hepatic stellate cell activity that is, in part, dependent on TNF- $\alpha$, presumably from the CD11c+ cells. ${ }^{102}$ The requirement for $C D 11 \mathrm{c}+$ cells in fibrosis was not tested. However, this study suggested that dendritic cells or other $\mathrm{CD} 11 \mathrm{c}+$ cells could potentially contribute to the inflammatory aspects of fibrosis. The contribution to fibrosis-associated inflammation is reminiscent of the proposed role of renal CD11c+ cells in the study discussed above, ${ }^{104}$ and it is possible that the two studies are describing related cells in different organs. Of note, Gr1+CD11b+F4/80 myeloid cells were found by Karlmark and colleagues ${ }^{105}$ to accumulate in early $\mathrm{CCl} 4$-induced injury and late $\mathrm{CCl} 4$-mediated fibrosis. The accumulation of these cells was dependent on whether CCR2 and CCR2-/- mice had attenuated fibrosis that could be rescued by injection of Gr1+ cells. ${ }^{105}$ Whether these inflammatory monocytes are related to the CD11c+ cells described by Connolly and colleagues remains to be determined. ${ }^{102}$ It will also be of interest to understand whether long-term depletion of CD11c+ cells using tools such as the CD11C-DTR mice affects parameters of fibrosis. ${ }^{106,107}$

The role of dendritic cells in pathogenesis of scleroderma and fibrosis is still not fully understood. Evidence to date supports the idea that dendritic cells may contribute to a proinflammatory cytokine environment, resulting in 
abnormally high levels of IL-10 similar to scleroderma patients ${ }^{108,109}$ and direct modulation of the activity of fibroblast-type cells. The proinflammatory role may be a double edged sword, as the inflammation that begets fibrosis may also be required for resolution of fibrosis. IL-10 may be responsible for both profibrotic and antifibrotic roles. ${ }^{2,110}$ The exact role of dendritic cells remains still to be determined.

\section{Conclusions}

Abnormal liver tests are common in patients with rheumatologic disorders. Liver test abnormalities include a hepatocellular injury pattern (increased aminotransferases), a cholestatic pattern (increased ALP with or without increased bilirubin), and a mixed picture. Evaluation does not often reveal an identifiable cause of the biochemical abnormality. Such nonspecific abnormalities are likely to be of little clinical significance, and no specific management is required. Serious progressive liver injury does occur, more often in the context of a coexisting primary liver disease or pharmacotherapy. An underlying primary liver disease for which treatment might be beneficial (e.g., immunosuppressive drugs for autoimmune hepatitis, interferon for viral hepatitis, ursodeoxycolic acid for PBC) should be sought. Testing for AMA, anti-smooth muscle antibodies, and HCV may be particularly helpful. Increased frequency of liver testing after initiation of anti-rheumatic treatment should raise the suspicion for drug-induced liver injury, as many anti-rheumatic drugs have documented hepatotoxicity and can cause reactivation of hepatitis $B$.

\section{Conflict of interest}

None

\section{Author contributions}

Designing and writing this manuscript (AAC, YAS, MA, KB).

\section{References}

[1] De Santis M, Crotti C, Selmi C. Liver abnormalities in connective tissue diseases. Best Pract Res Clin Gastroenterol 2013;27:543-551.

[2] Selmi C, Mackay IR, Gershwin ME. The immunological milieu of the liver. Semin Liver Dis 2007;27:129-139.

[3] Okuda K. Non-cirrhotic portal hypertension versus idiopathic portal hypertension. J Gastroenterol Hepatol 2002;17(Suppl 3):S204-213.

[4] Abraham S, Begum S, Isenberg D. Hepatic manifestations of autoimmune rheumatic diseases. Ann Rheum Dis 2004;63:123-129.

[5] Sandhu V, Jawad AS. Hepatic manifestations of autoimmune rheumatic diseases. Ann Rheum Dis 2004;63:1004-1005.

[6] Youssef WI, Tavill AS. Connective tissue diseases and the liver. J Clin Gastroenterol 2002;35:345-349.

[7] Al-Mukhaizeem KA, Rosenberg A, Sherker AH. Nodular regenerative hyperplasia of the liver: an under-recognized cause of portal hypertension in hematological disorders. Am J Hematol 2004;75:225-230.

[8] Wanless IR, Godwin TA, Allen F, Feder A. Nodular regenerative hyperplasia of the liver in hematologic disorders: a possible response to obliterative portal venopathy. A morphometric study of nine cases with an hypothesis on the pathogenesis. Medicine (Baltimore) 1980;59:367-379.

[9] Koren E, Schnitz W, Reichlin M. Concomitant development of chronic active hepatitis and antibodies to ribosomal $\mathrm{P}$ proteins in a patient with systemic lupus erythematosus. Arthritis Rheum 1993;36:1325-1328.

[10] Iwai M, Harada Y, Ishii M, Tanaka S, Muramatsu A, Mori T,et al. Autoimmune hepatitis in a patient with systemic lupus erythematosus. Clin Rheumatol 2003;22:234-236.
[11] Yamasaki S, Origuchi T, Nakata K, Toriyama K, Taguchi T, Ida H,et al. Autoimmune hepatitis in a patient with systemic lupus erythematosus: a case report. Mod Rheumatol 2004;14:169-173.

[12] Gonzalez LA, Orrego M, Ramirez LA, Vasquez G. Primary biliary cirrhosis/ autoimmune hepatitis overlap syndrome developing in a patient with systemic lupus erythematosus: a case report and review of the literature. Lupus $2011 ; 20: 108-111$

[13] Runyon BA, LaBrecque DR, Anuras $S$. The spectrum of liver disease in systemic lupus erythematosus. Report of 33 histologically-proved cases and review of the literature. Am J Med 1980;69:187-194.

[14] Gibson T, Myers AR. Subclinical liver disease in systemic lupus erythematosus. J Rheumatol 1981;8:752-759.

[15] Miller MH, Urowitz MB, Gladman DD, Blendis LM. The liver in systemic lupus erythematosus. Q J Med 1984;53:401-409.

[16] Ohira H, Takiguchi J, Rai T, Abe K, Yokokawa J, Sato Y, et al. High frequency of anti-ribosomal $\mathrm{P}$ antibody in patients with systemic lupus erythematosus-associated hepatitis. Hepatol Res 2004;28:137-139.

[17] Matsumoto T, Kobayashi S, Shimizu H, Nakajima M, Watanabe S, Kitami N, et al. The liver in collagen diseases: pathologic study of 160 cases with particular reference to hepatic arteritis, primary biliary cirrhosis, autoimmune hepatitis and nodular regenerative hyperplasia of the liver. Liver 2000;20:366-373.

[18] Fraile G, Rodriguez-Garcia JL, Moreno A. Primary sclerosing cholangitis associated with systemic sclerosis. Postgrad Med J 1991;67:189-192.

[19] Pedro-Botet J, Lopez MJ, Barranco C, Coll J, Bruguera M. Granulomatous hepatitis and giant cell arteritis. Am J Gastroenterol 1994;89:1898-1899.

[20] Watanabe Y, Mizukami T, Egawa T, Okamoto S, Sakauchi M, Takita T, et al. A case of progressive systemic sclerosis complicated by idiopathic portal hypertension with severe anemia. Ryumachi 1999;39:586-590.

[21] Dwornicki J, Luciak M. Spontaneous rupture of the liver in a patient with systemic lupus erythematosus. Pol Arch Med Wewn 1965;35:1645-1648.

[22] Haslock I. Spontaneous rupture of the liver in systemic lupus erythematosus. Ann Rheum Dis 1974;33:482-484.

[23] Boumpas DT, Austin HA, Fessler BJ, Balow JE, Klippel JH, Lockshin MD. Systemic lupus erythematosus: emerging concepts. Part 1: Renal, neuropsychiatric, cardiovascular, pulmonary, and hematologic disease. Ann Intern Med 1995;122:940-950.

[24] Sanchez-Urdazpal L, Czaja AJ, van Hoek B, Krom RA, Wiesner RH. Prognostic features and role of liver transplantation in severe corticosteroid-treated autoimmune chronic active hepatitis. Hepatology 1992;15: 215-221.

[25] Ebbeson RL, Schreiber RA. Diagnosing autoimmune hepatitis in children: is the International Autoimmune Hepatitis Group scoring system useful? Clin Gastroenterol Hepatol 2004;2:935-940.

[26] Johnson PJ, McFarlane IG. Meeting report: International Autoimmune Hepatitis Group. Hepatology 1993;18:998-1005.

[27] Desmet V], Gerber M, Hoofnagle JH, Manns M, Scheuer PJ. Classification of chronic hepatitis: diagnosis, grading and staging. Hepatology 1994;19: 1513-1520.

[28] Vergani D, Alvarez F, Bianchi FB, Cançado EL, Mackay IR, Manns MP, et al. Liver autoimmune serology: a consensus statement from the committee for autoimmune serology of the International Autoimmune Hepatitis Group. J Hepatol 2004;41:677-683.

[29] Hughes GR, Asherson RA, Khamashta MA. Antiphospholipid syndrome: linking many specialties. Ann Rheum Dis 1989;48:355-356.

[30] Hughes GR, Harris NN, Gharavi AE. The anticardiolipin syndrome. J Rheumatol 1986;13:486-489.

[31] Hughes GR, Khamashta MA. Anticardiolipin antibody. BM] 1989;299:14141415.

[32] McNeil HP, Simpson RJ, Chesterman CN, Krilis SA. Anti-phospholipid antibodies are directed against a complex antigen that includes a lipidbinding inhibitor of coagulation: beta 2-glycoprotein I (apolipoprotein $\mathrm{H}$ ). Proc Natl Acad Sci U S A 1990;87:4120-4124.

[33] Shoenfeld $Y$, Gharavi A, Koike T. Beta2GP-I in the anti phospholipid (Hughes') syndrome-from a cofactor to an autoantigen-from induction to prevention of antiphospholipid syndrome. Lupus 1998;7:503-506.

[34] Puri V, Bookman A, Yeo E, Cameron R, Heathcote EJ. Antiphospholipid antibody syndrome associated with hepatitis C infection. J Rheumatol 1999;26:509-510.

[35] Saeki R, Kaneko S, Terasaki S, Unoura M, Ogino H, Wakabayashi T,et al. Mixed types of chronic active hepatitis and primary biliary cirrhosis associated with the anti-phospholipid antibody syndrome: a case report. Hepatogastroenterology 1993;40:499-501.

[36] Beales IL. An acquired-pseudo Bernard Soulier syndrome occurring with autoimmune chronic active hepatitis and anti-cardiolipin antibody. Postgrad Med J 1994;70:305-308.

[37] Barak N, Orion Y, Schneider M, Bernheim J, Mekori YA. Case report: Hepatic involvement in antiphospholipid syndrome. J Gastroenterol Hepatol 1999 14:1124-1128. 
[38] Dourakis SP, Michael AE, Papanikolaou IS, Nomikou E, Thalassinou $P$ Hadziyannis SJ. Autoimmune hepatitis associated with the antiphospholipid syndrome. Eur ] Gastroenterol Hepatol 2001;13:591-593.

[39] Ordi-Ros J, Villarreal J, Monegal F, Sauleda S, Esteban I, Vilardell M. Anticardiolipin antibodies in patients with chronic hepatitis $C$ virus infection: characterization in relation to antiphospholipid syndrome. Clin Diagn Lab Immunol 2000;7:241-244.

[40] Prieto J, Yuste JR, Beloqui O,Civeira MP, Riezu JI, Aguirre B, et al. Anticardiolipin antibodies in chronic hepatitis C: implication of hepatitis $C$ virus as the cause of the antiphospholipid syndrome. Hepatology $1996 ; 23$ : 199-204.

[41] Yuste JR, Prieto J. Anticardiolipin antibodies in chronic viral hepatitis. Do they have clinical consequences? Eur J Gastroenterol Hepatol 2003;15: 717-719.

[42] Asherson RA, Cervera R. Review: antiphospholipid antibodies and the lung. J Rheumatol 1995;22:62-66.

[43] Cervera R, Asherson RA, Lie JT. Clinicopathologic correlations of the antiphospholipid syndrome. Semin Arthritis Rheum 1995:24:262-272.

[44] Gordon DA, Stein JL, Broder I. The extra-articular features of rheumatoid arthritis. A systematic analysis of 127 cases. Am J Med 1973;54:445-452.

[45] Sienknecht CW, Urowitz MB, Pruzanski W, Stein HB. Felty's syndrome. Clinical and serological analysis of 34 cases. Ann Rheum Dis 1977;36:500507.

[46] Cockel R, Kendall MJ, Becker JF, Hawkins CF. Serum biochemical values in rheumatoid disease. Ann Rheum Dis 1971;30:166-170.

[47] Webb J, Whaley K, MacSween RN, Nuki G, Dick WC, Buchanan WW. Liver disease in rheumatoid arthritis and Sjogren's syndrome. Prospective study using biochemical and serological markers of hepatic dysfunction. Ann Rheum Dis 1975;34:70-81.

[48] Pettersson T, Lepantalo M, Friman C, Ahonen J. Spontaneous rupture of the liver in rheumatoid arthritis. Scand J Rheumatol 1986;15:348-349.

[49] Hocking WG, Lasser K, Ungerer R, Bersohn M, Palos M, Spiegel T. Spontaneous hepatic rupture in rheumatoid arthritis. Arch Intern Med $1981 ; 141: 792-794$

[50] Lefkovits AM, Farrow IJ. The liver in rheumatoid arthritis. Ann Rheum Dis $1955 ; 14: 162-169$.

[51] McMahon RF, Babbs C, Warnes TW. Nodular regenerative hyperplasia of the liver, CREST syndrome and primary biliary cirrhosis: an overlap syndrome? Gut 1989;30:1430-1433.

[52] Mills PR, MacSween RN, Dick WC, More IA, Watkinson G. Liver disease in rheumatoid arthritis. Scott Med J 1980;25:18-22.

[53] Rau R, Pfenninger K, Boni A. Proceedings: Liver function tests and liver biopsies in patients with rheumatoid arthritis. Ann Rheum Dis 1975;34: 198-199.

[54] Miller MH, Littlejohn GO, Davidson A, Jones B, Topliss DJ. The clinical significance of the anticentromere antibody. $\mathrm{Br}$ J Rheumatol 1987;26:1721.

[55] Ruderman EM, Crawford JM, Maier A, Liu JJ, Gravallese EM, Weinblatt ME. Histologic liver abnormalities in an autopsy series of patients with rheumatoid arthritis. Br J Rheumatol 1997;36:210-213.

[56] Rau R, Karger T, Herborn G, Frenzel H. Liver biopsy findings in patients with rheumatoid arthritis undergoing longterm treatment with methotrexate. J Rheumatol 1989;16:489-493.

[57] Caramella C, Avouac J, Sogni P, Puechal X, Kahan A, Allanore Y. Association between rheumatoid arthritis and primary biliary cirrhosis. Joint Bone Spine $2007 ; 74: 279-281$.

[58] Job-Deslandre C, Feldmann JL, Djian Y, Menkes CJ. Chronic hepatitis during rheumatoid arthritis. Clin Exp Rheumatol 1991;9:507-510.

[59] Ogata H, Tsuji H, Hashiguchi M, Azuma K, Shimono J, Fujishima M. Autoimmune cholangiopathy associated with rheumatoid arthritis. Hepatogastroenterology 2000;47:1533-1534.

[60] Goritsas C, Roussos A, Ferti A, Trigidou R. Nodular regenerative hyperplasia in a rheumatoid arthritis patient without felty's syndrome. J Clin Gastroenterol 2002;35:363-364.

[61] Sasajima T, Suzuki T, Mori K, Ichii O, Tai M, Ochiai $\mathrm{H}$, et al. A case of idiopathic portal hypertension associated with rheumatoid arthritis. Mod Rheumatol 2006;16:92-96.

[62] Koga T, Migita K, Miyashita T, Maeda Y, Nakamura M, Abiru S,et al. Determination of anti-cyclic citrullinated peptide antibodies in the sera of patients with liver diseases. Clin Exp Rheumatol 2008;26:121-124.

[63] Constantopoulos SH, Tsianos EV, Moutsopoulos HM. Pulmonary and gastrointestinal manifestations of Sjogren's syndrome. Rheum Dis Clin North Am 1992; 18:617-635.

[64] Whaley K, Goudie RB, Williamson J, Nuki G, Dick WC, Buchanan WW. Liver disease in Sjogren's syndrome and rheumatoid arthritis. Lancet 1970;1: 861-863.

[65] Skopouli FN, Barbatis C, Moutsopoulos HM. Liver involvement in primary Sjogren's syndrome. Br J Rheumatol 1994;33:745-748.
[66] Montano-Loza AJ, Crispin-Acuna JC, Remes-Troche JM, Uribe M. Abnormal hepatic biochemistries and clinical liver disease in patients with primary Sjogren's syndrome. Ann Hepatol 2007;6:150-155.

[67] Ramos-Casals M, Sanchez-Tapias JM, Pares A, Forns X, Brito-Zerón P, Nardi $\mathrm{N}$, et al. Characterization and differentiation of autoimmune versus vira liver involvement in patients with Sjogren's syndrome. J Rheumatol 2006; 33:1593-1599.

[68] Csepregi A, Szodoray P, Zeher M. Do autoantibodies predict autoimmune liver disease in primary Sjogren's syndrome? Data of 180 patients upon a 5 year follow-up. Scand J Immunol 2002;56:623-629.

[69] Alarcon-Segovia D, Diaz-Jouanen E, Fishbein E. Features of Sjogren's syndrome in primary biliary cirrhosis. Ann Intern Med 1973;79:31-36.

[70] Hansen BU, Lindgren S, Eriksson S, Henricsson V, Larsson A, Manthorpe R, et al. Clinical and immunological features of Sjogren's syndrome in patients with primary biliary cirrhosis with emphasis on focal sialadenitis. Acta Med Scand 1988;224:611-619.

[71] Jorgensen C, Legouffe MC, Perney P, Coste J, Tissot B, Segarra C, et al. Sicca syndrome associated with hepatitis $C$ virus infection. Arthritis Rheum 1996 39:1166-1171.

[72] Garcia-Carrasco M, Ramos M, Cervera R, Font J, Vidal J, Muñoz F], et al. Hepatitis C virus infection in 'primary' Sjogren's syndrome: prevalence and clinical significance in a series of 90 patients. Ann Rheum Dis 1997;56:173175.

[73] Ramos-Casals M, Garcia-Carrasco M, Cervera R, Rosas J, Trejo O, de la Red $G$,et al. Hepatitis $C$ virus infection mimicking primary Sjogren syndrome. A clinical and immunologic description of 35 cases. Medicine (Baltimore) 2001;80:1-8.

[74] Ramos-Casals M, Font J, Garcia-Carrasco M, Cervera R, Jiménez S, Trejo O, et al. Hepatitis $C$ virus infection mimicking systemic lupus erythematosus: study of hepatitis $C$ virus infection in a series of 134 Spanish patients with systemic lupus erythematosus. Arthritis Rheum 2000;43:2801-2806.

[75] Ramos-Casals M, Garcia-Carrasco M, Cervera R, Font J. Sjogren's syndrome and hepatitis C virus.Clin Rheumatol 1999;18:93-100.

[76] Albert J, Ott H, Lamberti A. Association of CRST syndrome, GougerotSjogren syndrome, thyroid hyperplasia and chronic persistent hepatitis. Schweiz Rundsch Med Prax 1983;72:324-328.

[77] Black CM. Systemic sclerosis (scleroderma). Introduction. Ann Rheum Dis 1991;50 (Suppl 4):837-838.

[78] LeRoy EC, Black C, Fleischmajer R, Jablonska S, Krieg T, Medsger TA Jr,et al. Scleroderma (systemic sclerosis): classification, subsets and pathogenesis. J Rheumatol 1988;15:202-205.

[79] Rigamonti C, Shand LM, Feudjo M, Bunn CC, Black CM, Denton CP, et al. Clinical features and prognosis of primary biliary cirrhosis associated with systemic sclerosis. Gut 2006;55:388-394.

[80] Marasini B, Gagetta M, Rossi V, Ferrari P. Rheumatic disorders and primary biliary cirrhosis: an appraisal of 170 Italian patients. Ann Rheum Dis 2001; 60:1046-1049.

[81] Akimoto S, Ishikawa O, Takagi H, Miyachi Y. Immunological features of patients with primary biliary cirrhosis (PBC) overlapping systemic sclerosis: a comparison with patients with PBC alone. J Gastroenterol Hepatol 1998; 13:897-901.

[82] Barron L, Wynn TA. Fibrosis is regulated by Th2 and Th17 responses and by dynamic interactions between fibroblasts and macrophages. Am J Physiol Gastrointest Liver Physiol 2011;300:G723-G728.

[83] Wynn TA. Cellular and molecular mechanisms of fibrosis. J Pathol 2008; 214:199-210

[84] Mosmann TR, Coffman RL. TH1 and TH2 cells: different patterns of lymphokine secretion lead to different functional properties. Annu Rev Immunol 1989;7:145-173.

[85] Zhou L, Ivanov, II, Spolski R, Min R, Shenderov K, Egawa T, et al. IL-6 programs $T(H)-17$ cell differentiation by promoting sequential engagement of the IL-21 and IL-23 pathways. Nat Immunol 2007;8:967-974.

[86] Volpe E, Servant N, Zollinger R, Bogiatzi SI, Hupé P, Barillot E, et al. A critical function for transforming growth factor-beta, interleukin 23 and proinflammatory cytokines in driving and modulating human $\mathrm{T}(\mathrm{H})-17$ responses. Nat Immunol 2008;9:650-657.

[87] Manel N, Unutmaz D, Littman DR. The differentiation of human $T(H)-17$ cells requires transforming growth factor-beta and induction of the nuclear receptor RORgammat. Nat Immunol 2008;9:641-649.

[88] Yang L, Anderson DE, Baecher-Allan C, Hastings WD, Bettelli E, Oukka M, et al. IL-21 and TGF-beta are required for differentiation of human $\mathrm{T}(\mathrm{H}) 17$ cells. Nature 2008;454:350-352.

[89] Korn T, Bettelli E, Oukka M, Kuchroo VK. IL-17 and Th17 Cells. Annu Rev Immunol 2009;27:485-517.

[90] Cucci A, Barbero P, Clerico M, Ferrero B, Versino E, Contessa G, et al. Proinflammatory cytokine and chemokine mRNA blood level in multiple sclerosis is related to treatment response and interferon-beta dose. J Neuroimmunol 2010;226:150-157 
[91] Durelli L, Conti L, Clerico M, Boselli D, Contessa G, Ripellino P, et al. T-helper 17 cells expand in multiple sclerosis and are inhibited by interferon-beta. Ann Neurol 2009;65:499-509.

[92] Tzartos JS, Friese MA, Craner MJ, Palace J, Newcombe J, Esiri MM, et al. Interleukin-17 production in central nervous system-infiltrating $T$ cells and glial cells is associated with active disease in multiple sclerosis. Am J Pathol $2008 ; 172: 146-155$.

[93] Lovett-Racke AE, Yang $Y$, Racke MK. Th1 versus Th17: are T cell cytokines relevant in multiple sclerosis? Biochim Biophys Acta 2011;1812:246-251.

[94] Kimura A, Kishimoto T. Th17 cells in inflammation. Int Immunopharmacol 2011:11:319-322.

[95] Pene J, Chevalier S, Preisser L, Vénéreau E, Guilleux MH, Ghannam S, et al. Chronically inflamed human tissues are infiltrated by highly differentiated Th17 lymphocytes. J Immunol 2008;180:7423-7430.

[96] Geremia A, Jewell DP. The IL-23/IL-17 pathway in inflammatory bowel disease. Expert Rev Gastroenterol Hepatol 2012;6:223-237.

[97] Raychaudhuri SP. Role of IL-17 in psoriasis and psoriatic arthritis. Clin Rev Allergy Immunol 2012;44:183-193.

[98] Ghoreschi K, Laurence A, Yang XP, Hirahara K, O'Shea JJ. T helper 17 cell heterogeneity and pathogenicity in autoimmune disease. Trends Immunol 2011;32:395-401.

[99] Lan RY, Salunga TL, Tsuneyama K,Lian ZX, Yang GX, Hsu W, et al. Hepatic IL-17 responses in human and murine primary biliary cirrhosis. J Autoimmun 2009;32:43-51.

[100] Fenoglio D, Bernuzzi F, Battaglia F, Parodi A, Kalli F, Negrini S, et al. Th17 and regulatory $T$ lymphocytes in primary biliary cirrhosis and systemic sclerosis as models of autoimmune fibrotic diseases. Autoimmun Rev 2012; $12: 300-304$.
[101] Lu TT. Dendritic cells: novel players in fibrosis and scleroderma. Curr Rheumatol Rep 2012;14:30-38.

[102] Connolly MK, Bedrosian AS, Mallen-St Clair J, Mitchell AP, Ibrahim J, Stroud $A$, et al. In liver fibrosis, dendritic cells govern hepatic inflammation in mice via TNF-alpha. J Clin Invest 2009;119:3213-3225.

[103] Bataller R, Brenner DA. Liver fibrosis. ] Clin Invest 2005;115:209-218.

[104] Dong X, Bachman LA, Miller MN, Nath KA, Griffin MD. Dendritic cells facilitate accumulation of IL-17 T cells in the kidney following acute renal obstruction. Kidney Int 2008;74:1294-1309.

[105] Karlmark KR, Weiskirchen R, Zimmermann HW, Gassler N, Ginhoux F, Weber $\mathrm{C}$,et al. Hepatic recruitment of the inflammatory Gr1+ monocyte subset upon liver injury promotes hepatic fibrosis. Hepatology 2009;50: 261-274.

[106] Tzeng TC, Chyou S, Tian S, Webster B, Carpenter AC, Guaiquil VH,et al. $\mathrm{CD} 11 \mathrm{c}(\mathrm{hi})$ dendritic cells regulate the re-establishment of vascular quiescence and stabilization after immune stimulation of lymph nodes. J Immunol 2010;184:4247-4257.

[107] Zammit DJ, Cauley LS, Pham QM, Lefrancois L. Dendritic cells maximize the memory CD8 T cell response to infection. Immunity 2005;22:561570.

[108] Hasegawa M, Fujimoto M, Kikuchi K, Takehara K. Elevated serum levels of interleukin 4 (IL-4), IL-10, and IL-13 in patients with systemic sclerosis. J Rheumatol 1997;24:328-332.

[109] Kucharz EJ, Brzezinska-Wcislo L, Kotulska A, Gasiorowska-Kielkowska W, Gozdzik J. Elevated serum level of interleukin-10 in patients with systemic sclerosis. Clin Rheumatol 1997;16:638-639.

[110] Barbarin V, Xing Z, Delos M, Lison D, Huaux F. Pulmonary overexpression of IL-10 augments lung fibrosis and Th2 responses induced by silica particles. Am J Physiol Lung Cell Mol Physiol 2005;288:L841-L848. 